\title{
Individual differences in zoo-housed squirrel monkeys' (saimiri sciureus) reactions to visitors, research participation, and personality ratings
}

Polgar, Zita

Wood, Lara A.

Haskell, Marie

This is the peer reviewed version of the following article:

Polgar, Z., Wood, L.A., and Haskell, M. 2017. Individual differences in zoo-housed squirrel monkeys' (saimiri sciureus) reactions to visitors, research participation, and personality ratings. American Journal of Primatology.

which has been published in final form at doi:

https://dx.doi.org/10.1002/ajp.22639

This article may be used for non-commercial purposes in accordance with the Wiley Terms and Conditions for Self-Archiving

(https://authorservices. wiley.com/author-resources/Journal-Authors/licensing-andopen-access/open-access/self-archiving.html) 
5

Individual Differences in Zoo-housed Squirrel Monkeys' (Saimiri sciureus) Reactions to Visitors, Research Participation, and Personality Ratings

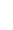

Zita Polgár ${ }^{\mathrm{a}}$, Lara Wood ${ }^{\mathrm{b} *}$, Marie J. Haskell ${ }^{\mathrm{c}}$

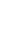

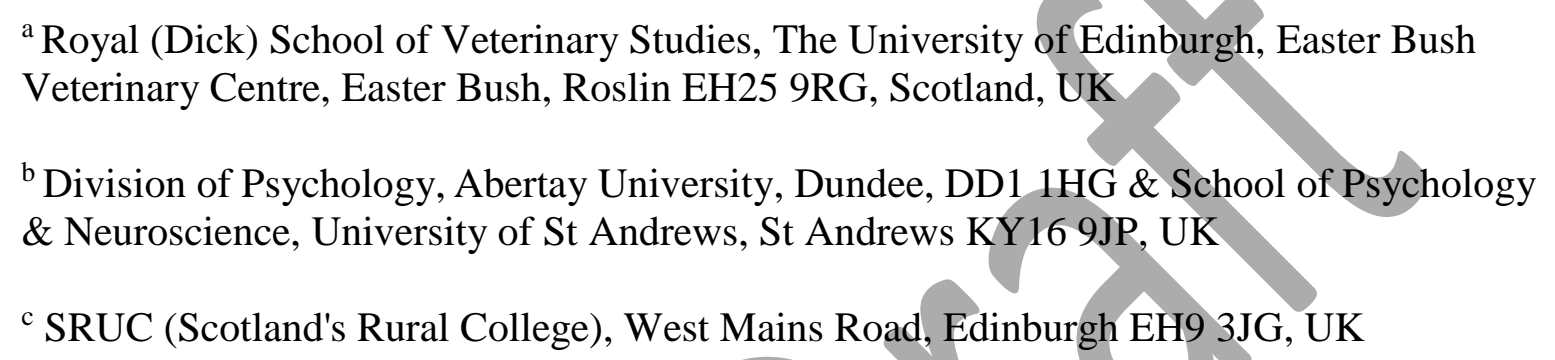

Phone: 01382308583 


\section{ABSTRACT}

Understanding individual differences in captive squirrel monkeys is a topic of importance both for improving welfare by catering to individual needs, and for better understanding the results and implications of behavioral research. In this study, 23 squirrel monkeys (Saimiri sciureus), housed in an environment that is both a zoo enclosure and research facility, were assessed for (i) the time they spent by an observation window under three visitor conditions: no visitors, small groups, and large groups, and (ii) their likelihood of participating in voluntary research, and (iii) zookeepers ratings of personality. A Friedman's ANOVA and Wilcoxon post-hoc tests comparing mean times found that the monkeys spent more time by the window when there were large groups present than when there were small groups or no visitors. Thus, visitors do not seem to have a negative effect and may be enriching for certain individuals. Through GLMM and correlational analyses, it was found that high scores on the personality trait of playfulness and low scores on cautiousness, depression, and solitude were significant predictors of increased window approach behavior when visitors were present. The GLMM and correlational analyses assessing the links between personality traits and research participation found that low scores of cautiousness and high scores of playfulness, gentleness, affection, and friendliness, were significant predictors. The implications of these results are discussed in relation to selection bias and its potential confounding effect on cognitive studies with voluntary participation. 


\section{RESEARCH HIGHLIGHTS}

- Squirrel monkey personality ratings correlated with response to visitors and research participation.

- Monkeys approached a viewing window more when visitors were present.

- Personality differences in research participation may cause selection bias.

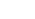

(1)

5

$$
\text { allow the animals to be viewed by humans [Hosey, 2005; Fernandez et al., 2009]. As the }
$$
maintenance of the animals cannot be supported without visitor revenue, and thus high visitor numbers are encouraged, it is important to assess what influence the presence of those visitors has on zoo animal welfare. The "visitor effect," which argues that animals behave differently when in the presence of human observers than when alone, has been measured across a variety of species in zoos all around the world (for a review, see [Hosey, 2000]). While assessments of non-primate species have generally found that visitors have little impact on animal behavior [Margulis et al., 2003; Quadros et al., 2014], studies on primates have concluded that visitors have a negative influence, finding that human presence generally causes increases in stress-related behaviors, such as attempting to hide, clinging to each other, and aggression [Chamove et al., 1988; Mitchell et al., 1992b; Birke, 2002; Keane \& Marples, 2003; Davis et al., 2005].

However, there are a number of factors that can reduce the visitor effect. Providing zoo animals with enrichment, such as feedings designed to promote foraging (i.e. scattering 
food in hay or hiding it in trees), has been shown to reduce the amount of visitor-induced anxiety and other abnormal behaviors that are expressed [Carder \& Semple, 2008; Izzo et al., 2011]. Enclosure design is also of vital importance in determining how animals respond to the presence of visitors. Animals that have greater control over their exposure to humans, by having off-show areas or retreat spaces for example, display fewer stress-related behaviors than those animals that do not have control[Anderson et al., 2002; Hosey, 2008; Smith \& Kuhar, 2010].

A clear example of this can be seen in two studies of orangutan (Pongo pygmaeus) welfare that came to starkly contrasting conclusions. One study at Singapore Zoo found that the presence of visitors generally had little effect on the orangutans, but that visitors who were especially active seemed to increase the frequency of play and feeding, behaviors that the authors interpreted as positive [Choo et al., 2011]. Meanwhile, another study at Chester Zoo found that high visitor numbers correlated with stress related behaviors like covering their heads with paper sacks and clinging more closely to each other [Birke, 2002]. Choo et al. suggest that this discrepancy may have been due to Singapore Zoo's unusual freeranging exhibit design. That enclosure, in addition to allowing the animals more freedom and enrichment, also allowed them a greater sense of security as they were in trees high above visitors rather than being at eye-level with or beneath humans as in other enclosures [Choo et al., 2011]. Having control over their interactions with visitors may be part of the reason why these orangutans did not display the stress behaviors found at other zoos.

There may also be individual differences in the reactions of primates to visitors, although few studies have examined this. Determining how individual animals respond to visitors allows for better individual management. For example, if keepers determine that 
92 visitors cause one individual to display fear-related behaviors while they cause another

93 individual to engage in play behaviors, the keepers can modify the enclosures and visitor

94 interactions to either decrease or increase the amount of exposure to people, for example by

95 either adding or removing visual barriers in the viewing area. Personality scoring of non-

96 human primates by familiar observers has been established as a useful tool for predicting

97 consistent individual differences in behavior [Weiss et al., 2009; Watters \& Powell, 2012;

98 Morton et al., 2013b; Pritchard et al., 2014]. In a study on gorillas (Gorilla gorilla) for

99 example, factor scores derived from keeper-rated personality assessments were found to

100 correlate with behaviors relating to visitor crowd size [Stoinski et al, 2012]. In some

101 studies on captive primates, age and sex have also been found to influence how the animals

102 respond to visitors, indicating that those factors should be taken into account as well

103 [Mitchell et al., 1991b, 1992a].

104 Individual differences are not only relevant in the zoo setting but also in research

105 participation. Taking individual differences into account is a vital point of investigation in

106 facilities where primates are given the opportunity to voluntarily participate in studies. In

107 these situations, data only comes from individuals who choose to take part. While this is

108 important from a welfare perspective, it leads to selection bias. [Morton et al., 2013a].

109 Gaining greater knowledge of individual differences allows for a better understanding of

110 not only the animals themselves but also of how they impact research. We hypothesize that

111 animals with more social and playful characteristics are more likely to voluntarily

112 participate in interactive research studies than less social and more fearful animals. This

113 could possibly skew the results of many studies as, on account of their different

114 personalities, the animals could have different problem-solving and behavioral tendencies. 
In the present study, there was a unique opportunity to assess the connections between these three topics -zoo visitor effects, research participation, and individual differences - by studying squirrel monkeys in an area that is both a zoo exhibit as well as a research facility. The 'Living Links to Human Evolution' Research Centre within the Royal Zoological Society of Scotland, Edinburgh Zoo (hereafter Living Links) houses two mixedspecies groups of capuchin and squirrel monkeys (see: [Macdonald \& Whiten, 2011]). The monkeys are given regular (normally daily) environmental enrichment and also have the opportunity to partake in research that requires problem solving or social learning, which provides them with enrichment in the form of mental stimulation. These sessions also allow for greater numbers of positive interactions with a variety of familiar and less familiar humans than most zoo-housed primates receive. This can lead to the monkeys being enriched by human presence, or at the very least having a non-aversive relationship with them [Hosey, 2008]. Research concerning individual differences in the squirrel monkeys has been ongoing [Wilson et al., in prep; Wilson, 2011], but thus far has not been investigated with regards to either reactions to visitors or participation in research.

The goals of this study were threefold: (1) to assess group level reactions to different visitor groups, (2) to assess individual differences in personality and reactions to visitors, (3) to investigate the relationship between personality and research participation. We predicted that (1) due to their high levels of enrichment, their opportunities to regulate their exposure to visitors, and their frequent interactions with keepers and researchers, the monkeys in this study would not react aversively to visitors, as measured by a lack of avoidance of the observation window as visitor numbers increased, (2) the monkeys would show individual differences as measured by consistent ratings of personality traits by the 
138 keepers and differences in responses to visitors, (3) monkeys who were scored by their

139 keepers as being highly friendly, playful, and curious would be more likely to come to the

140 observation window when visitors were present than those individuals who the keepers

141 scored as more timid or anxious, and a similar trend with regards to which animals would

142 be most likely to voluntarily participate in studies involving the research cubicles.

143

144

\section{METHODS}

\section{Subjects and Enclosure}

The subjects of this study were 23 of the 26 squirrel monkeys (Saimiri sciureus) housed within the 'Living Links to Human Evolution' Research Centre within the Royal Zoological Society of Scotland, Edinburgh Zoo. The monkeys were housed in two separate but identical mirror-image enclosures ('West', $\mathrm{N}=9$ and 'East,', $\mathrm{N}=17$, Figure 1). All of the monkeys were female, except for one alpha male in each group, identified by their larger sizes. The remaining monkeys, except for one juvenile in the West group (who was identified by her smaller size), were identified through different colored beads on their necklaces. Three of the monkeys in the East group who had lost their necklaces and could not be differentiated were excluded from the study. The monkeys ranged in age from one to 16 years with a mean \pm SE age of $7 \pm 1$ years. All of the monkeys had been born in captivity and none had been hand-reared.

Each enclosure consisted of five areas: (1) an outdoor area, (2) an indoor area accessible by both the squirrel monkeys and a population of brown capuchin monkeys (Sapajus apella; 18 in West and 17 in East), (3) an indoor area that was exclusive to the squirrel monkeys, (4) a research room with testing cubicles located between the two indoor 
161 enclosures of each side, and (5) an off-show area with holding cages. The squirrel monkeys

162 were free to move between all these areas at all times, except for the research rooms, which

163 were only available during research and training sessions. All the indoor areas had two full-

164 wall windows: one facing the outdoor area and one observation window on the front wall

165 allowing visitors to look into the enclosure. All windows had slanting ledges that monkeys

166 could perch on. For a full description of the enclosure design, including light cycles,

167 temperatures, and construction materials, see Leonardi et al. [2010]. The focus of this study

168 was the two observation windows on the front walls looking into the two indoor enclosures

169 that were exclusive to the squirrel monkeys.

171 week. During these sessions, the monkeys were free to enter. The monkeys could be

172 voluntarily isolated for up to 15 minutes once during each session. During training and

173 research sessions monkeys were rewarded for entering the cubicles, isolating, and

174 participating in research. These rewards included sunflower seeds, raisins, peanuts and 175 mealworms.

\section{Data collection}

178 Window approaching behavior

179 In order to determine how the monkeys responded to visitor groups of different

180 sizes, the monkeys' use of the observation windows was examined to see how frequently

181 each monkey approached the window under the different conditions. There were three

182 mutually exclusive visitor group size conditions, as determined by previous studies on 
183 visitor demographics [Ridgway et al., 2006]: (1) no visitors, (2) small groups (one to three

184 people), and (3) large groups (four or more people).

185 During each observation session, the viewing window of one of the squirrel monkey

186 indoor enclosures (East or West) was observed continuously for 30 minutes by the same

187 observer (ZP). There were 80 data collection sessions (40 per enclosure) over six weeks

188 between the months of April and May 2015. Data was collected every other day always

189 between the hours of 13:00 and 17:00, but never during feeding, cleaning, or training.

190 There was no cubicle research during this time. There were four sessions (two per

191 enclosure) each data collection day, where the sessions alternated between East and West

192 observations. In order to minimize observer effect, prior to each session there was a 10-

193 minute period where the observer was present at the window but did not record data. This

194 time frame was determined based on the experiences of the zookeepers, as well as on

195 previous research that showed that primates habituate to the presence of non-visitor

196 observers within that time frame [Mitchell et al., 1991a].

197 The data was collected using the Time-stamped Field Data event recording

198 application (Neukadye, LLC. Version 1.3) on an iPad (Apple Inc.), which recorded the

199 duration of time that the various groups of visitors spent at the observation window, as well

200 as the duration of time that each monkey spent at the window during that time period. The

201 average proportion of time each monkey spent at the window for each visitor category was

202 then calculated from the total amount of time that visitor category was at the window across 203 the 40 sessions. 
POLGÁR 10

\section{Cubicle research participation}

Throughout the months of June and July 2015, a separate study was conducted requiring the voluntary isolation of the monkeys in the research cubicles. This study involved training sessions where the monkeys received food rewards for entering and remaining in the cubicles, as well as research sessions where the monkeys were given a novel object to interact with and food rewards for participation. The monkeys chose whether to enter the cubicles during the session and were given the option to return to the group if they showed signs of discomfort (for a more detailed description of the cubicle setup, see: [Macdonald \& Whiten, 2011]). Throughout these sessions, the order in which the monkeys chose to enter (or not) the cubicles was recorded for both groups as a measure of likeliness to participate. In these sorts of settings, individuals are often excluded from studies if they do not meet regular participation criteria, therefore the likelihood of participation is a relevant measure to assess [Morton et al., 2013a]. Each monkey was given a score based on their order of entry for each session. This was calculated by taking the total number of monkeys in each group (nine for West, 14 for East) and giving a reverse order score based on that number. For example, the first monkey to enter the cubicles in the West group would receive nine points, the second eight points and so forth, while the first monkey in the East group would receive 14 points, and the second 13. Monkeys who did not enter the cubicles received zero points. In order to make the scores of the two groups comparable, the scores for each monkey were divided by the total number of monkeys in its group. The final score for each monkey was the average of these ratios across all of the cubicle sessions (21 for the West Group, 18 for the East Group). 


\section{POLGÁR 11}

\section{Keeper-ratings of personality}

Three keepers who had worked with the monkeys for at least three years were asked to fill out a shortened version of the Hominoid Personality Questionnaire [Weiss et al., 2009] for each of the monkeys. This shortened version consisted of 12 personality traits for which each monkey was rated on a seven point Likert scale based on one to two descriptive sentences (Table 1). The directions on the questionnaire explained that a score of 1 indicated that the monkey displayed a "total absence or negligible amount" of that trait and a score of 7 indicated that the individual displayed "extremely large amounts" of that trait. The original questionnaire was reduced to 12 traits in order to accommodate the zookeepers' time restraints and to attempt to create a more practical and efficient version of the questionnaire. The personality traits were chosen based on high loadings found in a previous personality assessment of squirrel monkeys using the full 54-item Hominoid Personality Questionnaire. In that study, four components ('Assertiveness,' 'Impulsiveness,' 'Neuroticism,' and 'Agreeableness') were derived from 46 reliable items and were validated across 57 animals from eight international zoos [Wilson et al., in prep; Wilson, 2011]. Three high-loading traits were chosen from each of the four components. An attempt was made to choose traits that were distinct from each other and that had minimal overlap in their descriptive sentences.

\section{Statistical analysis}

To compare the proportion of time that the monkeys spent at the observation window for each of the three visitor categories, a Friedman's ANOVA and post-hoc Wilcoxon tests were used, as the distribution of the residuals proved to be non-normal. A 
Holm-Bonferroni sequential correction was applied to the results and the adjusted p-values are reported [Holm, 1979].

To identify the factors that influence the window approach behavior and participation in cubicle research, two generalized linear mixed models (GLMM) were run using IBM SPSS (Version 22). For the window approach behavior, a binomial distribution with a logit link function was used. For the cubicle participation data, a normal distribution with an identity link function was used. In both models, the random effects included Monkey ID nested within Enclosure. The fixed effects were determined by running the explanatory variables (each of the reliable personality traits and age) through the program's Automatic Linear Modeling function using a forward stepwise model selection method with an Akaike Information Criterion Corrected (AICc) information criterion. Each of the 12 personality traits was tested for inter-rater reliability between the three keepers using a two-way interclass mixed-model correlation $\left(\operatorname{ICC}_{(3, \mathrm{k})}\right)$ [Shrout \& Fleiss, 1979]. Correlational tests and graphical summaries were used to determine the relationships between the predictive and behavioral variables.

\section{Ethical consideration}

This study was approved by the Scientific Review Team of the University of Edinburgh. As the study was observational and there was no direct manipulation of, or interference with the animals, the team felt it was not necessary to receive approval from the Veterinary Ethical Review Committee (VERC). The study was also approved by the research review board at the 'Living Links to Human Evolution' Research Centre and the Royal Zoological Society of Scotland, Edinburgh Zoo. The research adhered to the 
POLGÁR 13

American Society of Primatologists (ASP) Principles for the Ethical Treatment of NonHuman Primates.

\section{Group level reaction to visitors}

\section{RESULTS}

There were significant differences between the mean proportions of time that the monkeys spent at the window during the three visitor group categories (Friedman's ANOVA: $\mathrm{X}_{(2)}^{2}=31.92, \mathrm{P}<0.001$, see Figure 2). The monkeys spent significantly larger proportions of time at the observation window when there were large groups of visitors present compared to when there were no visitors or small groups present (Wilcoxon: $\mathrm{Z}=-$ 4.009, $\mathrm{P}=0.002 ; \mathrm{Z}=-3.09, \mathrm{P}=0.002)$. The monkeys also spent a greater proportion of time at the observation window when there were small groups of visitors there compared to when there were no visitors (Wilcoxon: $\mathrm{Z}=-3.444, \mathrm{P}=0.001$ ).

\section{Individual differences in reactions to visitors} There were considerable individual differences between the monkeys with regards to their proportions of time spent at the window for each visitor category (Figure 3). The individual percentages of time spent at the window for the 'No Visitor' category ranged from $0 \%$ to $76 \%($ mean \pm SE: $18 \pm 3 \%$ ). The individual percentages of time that monkeys spent at the window for the 'Small Group' category ranged from $0 \%$ to $37 \%$ (mean $\pm \mathrm{SE}$ : $18 \pm 2 \%$ ), while the percentage of time for the 'Large Group' category ranged from $0 \%$ to $88 \%($ mean \pm SE: $59 \pm 5 \%$ ). The total amount of time each monkey spent at the window 
across all sessions ranged from zero minutes (one individual never came to the window) to 143 minutes (mean \pm SE: $27 \pm 6.5$ minutes).

\section{Relationship between personality, reaction to visitors, and research participation}

For the personality questionnaire scores, the inter-rater reliability of the mean ratings between the three keepers, $I C C_{(3, k)}$, had a mean of 0.38 , and ranged from 0.138 for depressed to 0.729 for playful. One trait (predictable) that had an ICC value that was less than zero was considered unreliable (as per the criteria used by other studies of primate personality - see: [Weiss et al., 2011; Wilson, 2011]) and was removed from further analysis. All raters completed the questionnaires fully and there were no missing values.

For the data on the proportion of time spent at the viewing window, the Automatic Linear Modeling function showed that the personality traits playful, cautious, solitary, dominant, and depressed had the highest associations (adjusted $\mathrm{R}^{2}=0.30$ ). All of these traits, except for dominant, had significant effects (Table 2). In order to determine the direction of the effects, Spearman's correlations were run between the significant traits and the difference between the proportion of time spent at the window during the 'Large Group' condition and the 'No Visitor' condition. Playfulness was found to have a positive relationship $(\mathrm{R}=0.162)$ while cautious $(\mathrm{R}=-0.042)$, solitary $(\mathrm{R}=-0.419)$, and depressed $(\mathrm{R}=-$

\subsection{7) had negative relationships (Figure 4).}

For the cubicle research participation data, the Automatic Linear Modelling function determined that playful, cautious, affectionate, friendly, and gentle were the traits of greatest importance (adjusted $R^{2}=0.668$ ). When these were assessed for their significance in predicting research participation, it was found that all had significant effects (Table 2). 
317 Pearson's correlations showed that playful $(\mathrm{R}=0.729)$, affectionate $(\mathrm{R}=0.405)$, friendly

$318(\mathrm{R}=0.447)$, and gentle $(\mathrm{R}=0.487)$ had positive relationships with cubicle participation

319 scores, while cautious $(\mathrm{R}=-0.341)$ had a negative relationship (Figure 5).

320

\section{DISCUSSION}

The goals of this study were threefold: (1) to assess group level reactions to different visitor groups, (2) to assess individual differences in personality and reactions to visitors, (3) to investigate the relationship between personality and research participation.

Our first prediction that the monkeys would not react aversively to visitors was broadly supported. On average, the more people there were at the observation window, the more frequently the monkeys chose to come up to that window. This implies that the monkeys are actively choosing to be around the visitors when they are at the viewing window, as they could easily choose to be in other areas without visitors if they found them aversive. Thus, the visitors do not seem to have a negative impact on their welfare and may even be enriching for some of the individuals. However, previous studies [Mitchell et al., 1992c; Hosey, 2000] investigating relationships between animal behaviors and visitor presence rightfully note the importance of not assuming causality, arguing that zoo visitors may be attracted to animals performing certain behaviors.

This is unlikely to be the case for this study for a number of reasons. Firstly, the setup of the enclosures (Figure 1) is such that visitors are not able to see the animals in the indoor enclosure until they are already directly at the window, making it unlikely that the sight of unusual animal behaviors are attracting the larger numbers of visitors to the window from other areas. Additionally, the visitors are not able to see how many other 
340 people are at the window until they are there themselves. This makes it unlikely that the

341 presence of crowds looking at interesting behaviors, such as monkeys that are up on the

342 ledge, were attracting more people to the window. Furthermore, the results showed that,

343 when there is no one around, the monkeys do not choose to spend much time up on the

344 ledge, suggesting once again that when they do come up to the window, it is to be closer to 345 the visitors.

346 All of these factors provide support for the conclusion that, for the squirrel monkeys

347 at this facility, the presence of zoo visitors does not appear to negatively influence their

348 welfare and that some individuals may even actively seek it out. This conclusion stands in

349 contrast to the results of the majority of previous primate studies (though not all - see:

350 [Cook \& Hosey, 1995; Todd et al., 2007]) suggesting that the presence of humans is

351 primarily a source of stress for the animals [Chamove et al., 1988; Birke, 2002; Keane \&

352 Marples, 2003; Wells \& Blaney, 2003; Davis et al., 2005; Mallapur et al., 2005]. A number

353 of possibilities could explain this discrepancy. First, the squirrel monkeys in this study are

354 provided with a variety of enrichment opportunities, which has been suggested to reduce

355 stress in some species [Carder \& Semple, 2008; Izzo et al., 2011]. Second, they have

356 frequent positive interactions with humans through other research studies, potentially

357 fostering in them a positive human-animal relationship, thus reducing the 'visitor effect'

358 [Hosey, 2008]. Lastly, the animals had the option to choose from five different enclosure

359 areas with different levels of exposure to zoo visitors. This allowed some monkeys to come

360 into very close proximity to humans, for example by jumping up to the ledge by the

361 viewing window, while allowing other monkeys to avoid them completely. 
Our second prediction that the monkeys would show individual differences was largely supported. Apart from the trait of predictable, all other traits had positive ICC ratings. The trait of playful had a particularly strong ICC rating. Similarly, there was a huge variance in the amount of time that individuals chose to be at the window. These individual differences were also found to have significant influences on how the monkeys behaved. As such, our third and fourth hypotheses that personality ratings would be associated with visitor reactions and research participation were also supported. For both approaching the window and participating in research, higher scores of playfulness and lower scores of cautiousness were important factors. This makes sense intuitively, as it is logical that cautious animals would be less inclined to engage in activities that put them in close proximity to relatively unpredictable humans, and that playful animals might see engaging in those same activities as rewarding.

Interestingly, the remaining relevant personality traits for the two behaviors fell on opposite spectrums. While for the window approaching behaviors the significant predictive personality scores (correlated with less time spent at the window) were for solitude and depression, both of which are highly loading on the 'Neuroticism' factor [Wilson et al., in prep.], for predicting the monkeys' participation in research, it was the traits that were highly loading on the 'Agreeableness' factor (gentle, affectionate, and friendly) that proved to be significant. The suggestion that more neurotic animals do not come to the observation window more frequently when there are visitors present could have welfare implications. It is possible that those animals are simply not interested in the visitors and thus have no motivation to interact with them, or they may find the visitors aversive and are actively avoiding them. More studies are needed to make this distinction. 
The relationship between personality scores and research participation also has important practical implications, particularly in relation to the existence of selection bias in behavioral research studies. The behavior of the more agreeable animals during the research sessions may be different from the behavior of the non-participating and evidently less agreeable individuals. Indeed, studies have found that individuals with more assertive or aggressive personalities have different problem-solving strategies compared to less assertive individuals. This was demonstrated by a study done with the very capuchins housed with these squirrel monkeys, which found that accuracy was negatively correlated with scores of assertiveness in a number of cubicle-based tasks [Morton et al., 2013a].

Studies on chimpanzees (Pan troglodytes) have also found that a variety of personality dimensions can have strong correlations with behavioral measures on cognitive tests [Weiss et al., 2012; Reamer et al., 2014; Brosnan et al., 2015]. Agreeableness, for example, was found to be correlated with responses to inequity, where chimpanzees with lower ratings of Agreeableness were more likely to respond to inequity by refusing to exchange rewards than those with higher ratings in that dimension [Brosnan et al., 2015]. The existence of personality differences between the monkeys, and the knowledge that these differences may influence not only which monkeys participate in research but also their performance within the tests themselves, suggests that these differences need to be taken into account much more frequently in order to avoid the confounding effects of selection bias.

While the results of this study may provide valuable insights for future research and welfare management, it is important to acknowledge its limitation. For example, the amount of choice in enclosure location was a potential confound for the current study. 
Because the monkeys had many other areas that they could choose to be in, measuring their response to visitors at only one of these spaces may not have been representative of their true overall response. It is possible that, on occasion, some monkeys could have chosen to interact with people in other areas, such as the observation window in the capuchin enclosures, and this would not have been recorded through the methodology of this study. Such an omission may be hiding potential relationships between monkey reactions to visitors and personality ratings.

There could also be some confounds in the personality ratings, as the keepers who filled them out have inherently different types of interactions with the monkeys than the visitors. Primates can differentiate between keepers or observers and unfamiliar visitors [Mitchell et al., 1991a]. Because the keepers only see the monkeys when the monkeys are around people they are familiar with (themselves), their assessments of personality may be biased towards those types of situations and may be less able to predict the monkeys' personalities around unfamiliar visitors. This may also explain why personality ratings were found to account for a greater portion of the variance in research participation data, where the monkeys were in situations with familiar keepers and researchers, than for the data from the window approach behavior, which measured interactions with strangers.

Of course, the relatively small sample size of the study should be taken into account before generalizing to other populations of squirrel monkeys. In particular, the inequality between the number of male and female monkeys should be noted, as the present study had only two male individuals. Future research should assess squirrel monkey populations across multiple zoos and institutions and should have larger representation of males in 
430 order to examine the potential effects of sex on individual differences in behavior and 431 personality.

432 449 visitor-effect and research participation.

\section{CONCLUSIONS}

This study demonstrates that individual differences exist between squirrel monkeys both in how they respond to varying sizes of zoo visitor groups, and in their likeliness to participate in voluntary behavioral research. While, on average, visitors do not seem to have a negative impact on the welfare of the animals, certain individuals choose to engage with humans more than others, and management practices should take these individual welfare needs into account. Potential ways of doing this would be to design enclosures in such a way that animals could choose to have close-up interactions with visitors via viewing windows, while still maintaining enclosure elements that allow for visitor avoidance. Offering voluntary participation in training sessions or research studies could also prove to be beneficial for some individuals. Keeper ratings based off of personality questionnaires could also be used to predict animal behaviors. With regards to future primate studies, the relationship between personality ratings and research participation suggests that there is a strong possibility for selection bias to occur; therefore, care should be taken in accounting for this issue. Lastly, further study with larger sample sizes and more in-depth personality assessments would shed more light onto what factors influence 
452 This study could not have been done without the support of everyone at the 'Living Links 453 to Human Evolution' Research Centre, particularly the zookeepers - Amanda Dennis, 454 Debbie Bryson, and Jennifer Quigg - who filled out the questionnaires, as well as 455 Samantha Babcock who collected data on the monkeys' participation in cubicle research. 456 We would also like to thank Jessica Martin for her statistical guidance and Vanessa Wilson 457 for her comments on the manuscript. 


\section{REFERENCES}

Anderson US, Benne M, Bloomsmith MA, Maple TL. 2002. Retreat space and human visitor density moderate undesirable behavior in petting zoo animals. Journal of Applied Animal Welfare Science 5:125-137.

Birke L. 2002. Effects of browse, human visitors and noise on orangutans. Animal Welfare $11: 189-202$.

Brosnan SF, Hopper LM, Richey S, et al. 2015. Personality influences responses to inequity and contrast in chimpanzees. Animal Behaviour 101:75-87.

Carder G, Semple S. 2008. Visitor effects on anxiety in two captive groups of western lowland gorillas. Applied Animal Behaviour Science 115:211-220.

Chamove AS, Hosey GR, Schaetzel P. 1988. Visitors excite primates in zoos. Zoo Biology 7:359-369.

Choo Y, Todd PA, Li D. 2011. Visitor effects on zoo orangutans in two novel, naturalistic enclosures. Applied Animal Behaviour Science 133:78-86.

Cook S, Hosey GR. 1995. Interaction sequences between chimpanzees and human visitors at the Zoo. Zoo Biology 14:431-440.

Davis N, Schaffner CM, Smith TE. 2005. Evidence that zoo visitors influence HPA activity in spider monkeys (Ateles geoffroyii rufiventris). Applied Animal Behaviour Science 90:131-141.

Fernandez EJ, Tamborski MA, Pickens SR, Timberlake W. 2009. Animal-visitor interactions in the modern zoo: Conflicts and interventions. Applied Animal Behaviour Science 120:1-8.

Holm S. 1979. A simple sequential rejective method procedure. Scandinavian Journal of 
Statistics 6:65-70.

Hosey GR. 2000. Zoo animals and their human audiences: What is the visitor effect? Animal Welfare 9:343-357.

Hosey GR. 2005. How does the zoo environment affect the behaviour of captive primates? Applied Animal Behaviour Science 90:107-129.

Hosey GR. 2008. A preliminary model of human-animal relationships in the zoo. Applied Animal Behaviour Science 109:105-127.

Izzo GN, Bashaw MJ, Campbell JB. 2011. Enrichment and individual differences affect welfare indicators in squirrel monkeys (Saimirisciureus). Journal of Comparative Psychology 125:347-52.

Keane C, Marples N. 2003. The effects of zoo visitors on gorilla behaviour. Proceedings of The Fifth Annual Symposium on Zoo Research 1:144-154.

Leonardi R, Buchanan-Smith HM, Dufour V, MacDonald C, Whiten A. 2010. Living together: behavior and welfare in single and mixed species groups of capuchin (Cebus apella) and squirrel monkeys (Saimiri sciureus). American Journal of Primatology $72: 33-47$.

Living Links to Human Evolution Research Centre. 2014. Study Site. Available from: http://www.living-links.org/resources/

Macdonald C, Whiten a. 2011. The "Living Links to Human Evolution" Research Centre in Edinburgh Zoo: A new endeavour in collaboration. International Zoo Yearbook 45:7-17.

Mallapur A, Sinha A, Waran N. 2005. Influence of visitor presence on the behaviour of captive lion-tailed macaques (Macaca silenus) housed in Indian zoos. Applied Animal 
Behaviour Science 94:341-352.

505

506

507

Margulis SW, Hoyos C, Anderson M. 2003. Effect of felid activity on zoo visitor interest. Zoo Biology 22:587-599.

Mitchell G, Herring F, Obradovich S. 1992a. Like threaten like in mangabeys and people? Anthrozoös 5:106-112.

Mitchell G, Herring F, Tromborg C, et al. 1992b. Targets of aggressive facial displays by golden-bellied mangabeys (Cercocebus galeritus chrysogaster) at the Sacramento Zoo. Applied Animal Behaviour Science 33:249-259.

Mitchell G, Obradovich SD, Herring FH, Dowd B, Tromborg C. 1991a. Threats to observers, keepers, visitors, and others by zoo mangabeys (Cercocebus galeritus chrysogaster). Primates 32:515-522.

Mitchell G, Steiner S, Dowd B, Tromborg C, Herring F. 1991b. Male and female observers evoke different responses from monkeys. Bulletin of the Psychonomic Society $29: 358-360$.

Mitchell G, Tromborg C, Kaufman J, Bargabus S, Geissler V. 1992c. Short Communication: More on the "influence" of zoo visitors on the behaviour of captive primates. Applied Animal Behaviour Science 35:189-198.

Morton F, Lee P, Buchanan-Smith HM. 2013a. Taking personality selection bias seriously in animal cognition research: a case study in capuchin monkeys (Sapajus apella). Animal Cognition 16:677-684.

Morton FB, Lee PC, Buchanan-Smith HM, et al. 2013b. Personality structure in brown capuchin monkeys (Sapajus apella): Comparisons with chimpanzees (Pan troglodytes), orangutans (Pongo spp.), and rhesus macaques (Macaca mulatta). 
Journal of Comparative Psychology 127:282-298.

Pritchard AJ, Sheeran LK, Gabriel KI, Li J-H, Wagner RS. 2014. Behaviors that Predict Personality Components in Adult free-Ranging Tibetan Macaques (Macaca thibetana). Current Zoology 60:362-372.

Quadros S, Goulart VDL, Passos L, Vecci M a. M, Young RJ. 2014. Zoo visitor effect on mammal behaviour: Does noise matter? Applied Animal Behaviour Science 156:7884.

Reamer LA, Haller RL, Thiele EJ, et al. 2014. Factors affecting initial training success of blood glucose testing in captive chimpanzees (Pan troglodytes). Zoo Biology 33:212220.

Ridgway SC, Livingston M, Smith SE. 2006. Visitor behavior in zoo exhibits with underwater viewing. Visitor Studies Today 8:1-10.

Shrout PE, Fleiss JL. 1979. Intraclass correlations: Uses in assessing rater reliability. Psychological Bulletin 86:420.

Smith KN, Kuhar CW. 2010. Siamangs (Hylobates syndactylus) and white-cheeked gibbons (Hylobates leucogenys) show few behavioral differences related to zoo attendance. Journal of Applied Animal Welfare Science 13:154-63.

Stoinski TS, Jaicks HF, Drayton LA. 2012. Visitor effects on the behavior of captive Western lowland gorillas: the importance of individual differences in examining welfare. Zoo Biology 31:586-99.

Todd P a., Macdonald C, Coleman D. 2007. Visitor-associated variation in captive Diana monkey (Cercopithecus diana diana) behaviour. Applied Animal Behaviour Science 107:162-165. 
POLGÁR 26

Watters J V, Powell DM. 2012. Measuring animal personality for use in population management in zoos: suggested methods and rationale. Zoo Biology 31:1-12.

Weiss A, Adams MJ, Widdig A, Gerald MS. 2011. Rhesus macaques (Macaca mulatta) as living fossils of hominoid personality and subjective well-being. Journal of Comparative Psychology 125:72-83.

Weiss A, Inoue-Murayama M, Hong K-W, et al. 2009. Assessing chimpanzee personality and subjective well-being in Japan. American Journal of Primatology 71:283-92.

Weiss A, Inoue-Murayama M, King JE, Adams MJ, Matsuzawa T. 2012. All too human? Chimpanzee and orang-utan personalities are not anthropomorphic projections. Animal Behaviour 83:1355-1365.

Wells DL, Blaney EC. 2003. Camouflaging gorillas: a method of reducing the "visitor effect." Proceedings of The Fifth Annual Symposium on Zoo Research:332-333.

Wilson V. 2011. Personality and Social Interactions in Cebus apella and Saimiri sciureus (Doctoral dissertation). Retrieved from Edinburgh Research Archive. 2012-0713T14:33:21Z

Wilson V, Inoue-Murayama M, Weiss A. in prep. Comparative personality and well-being assessment in two species of squirrel monkey: Saimiri sciureus and Saimiri boliviensis. 
TABLE I. Personality traits and descriptive sentences that were presented to the keepers in the Squirrel Monkey Personality Questionnaire.

\begin{tabular}{|c|c|}
\hline Trait & Description \\
\hline Dominant & $\begin{array}{l}\text { Subject is able to displace, threaten, or take food from other monkeys. } \\
\text { Or subject may express high status by decisively intervening in social } \\
\text { interactions. }\end{array}$ \\
\hline Curious & $\begin{array}{l}\text { Subject has a desire to see or know about objects, devices, or other } \\
\text { monkeys. This includes a desire to know about the affairs of other } \\
\text { monkeys that do not directly concern the subject. }\end{array}$ \\
\hline Cautious & $\begin{array}{l}\text { Subject often seems attentive to possible harm or danger from its } \\
\text { actions. Subject avoids risky behaviors. }\end{array}$ \\
\hline Playful & $\begin{array}{l}\text { Subject is eager to engage in lively, vigorous, sportive, or acrobatic } \\
\text { behaviors with or without other monkeys. }\end{array}$ \\
\hline Solitary & $\begin{array}{l}\text { Subject prefers to spend considerable time alone not seeking or avoiding } \\
\text { contact with other monkeys. }\end{array}$ \\
\hline Gentle & $\begin{array}{l}\text { Subject responds to others in an easy-going, kind, and considerate } \\
\text { manner. Subject is not rough or threatening. }\end{array}$ \\
\hline Timid & $\begin{array}{l}\text { Subject lacks self-confidence, is easily alarmed and is hesitant to } \\
\text { venture into new social or non-social situations. }\end{array}$ \\
\hline Affectionate & $\begin{array}{l}\text { Subject seems to have a warm attachment or closeness with other } \\
\text { monkeys. This may entail frequent grooming, touching, embracing, } \\
\text { lying near others. }\end{array}$ \\
\hline Predi & $\begin{array}{l}\text { Subject's behavior is consistent and steady over extended periods of } \\
\text { time. Subject does little that is unexpected or deviates from its usual } \\
\text { routine. }\end{array}$ \\
\hline Depres & $\begin{array}{l}\text { Subject does not seek out social interactions with others and often fails } \\
\text { to respond to social interactions of other monkeys. Subject often appears } \\
\text { isolated, withdrawn, sullen, brooding, and has reduced activity. }\end{array}$ \\
\hline Friendly & $\begin{array}{l}\text { Subject often seeks out contact with other monkeys for amiable, genial } \\
\text { activities. Subject infrequently initiates hostile behaviors towards other } \\
\text { monkeys. }\end{array}$ \\
\hline Anxious & Subject often seems distressed, troubled, or is in a state of uncertainty. \\
\hline
\end{tabular}


POLGÁR 28

TABLE II. GLMM results showing significance of explanatory variables influencing the proportion of time spent at the viewing window and participation in research.

\begin{tabular}{|l|c|c|c|c|}
\hline & \multicolumn{2}{|c|}{$\begin{array}{c}\text { Time at Viewing } \\
\text { Window }\end{array}$} & \multicolumn{2}{c|}{$\begin{array}{c}\text { Research } \\
\text { Participation }\end{array}$} \\
\hline Trait & F & Sig & F & Sig \\
\hline Playful & 26.273 & $<\mathbf{0 . 0 0 1}$ & 59.335 & $<\mathbf{0 . 0 0 1}$ \\
\hline Cautious & 10.908 & $\mathbf{0 . 0 0 2}$ & 11.325 & $\mathbf{0 . 0 0 1}$ \\
\hline Solitary & 8.677 & $\mathbf{0 . 0 0 5}$ & - & - \\
\hline Dominant & 2.954 & 0.091 & - & - \\
\hline Depressed & 5.646 & $\mathbf{0 . 0 2 1}$ & - & - \\
\hline Affectionate & - & - & 7.844 & $\mathbf{0 . 0 0 7}$ \\
\hline Friendly & - & - & 7.803 & $\mathbf{0 . 0 0 7}$ \\
\hline Gentle & - & - & 7.289 & $\mathbf{0 . 0 0 9}$ \\
\hline \multicolumn{2}{|l}{ df1 =1 and df2 $=63$ for all values. }
\end{tabular}

\section{FIGURE LEGENDS}

Fig 1. Enclosure Setup. The East and West sides are identical but separate enclosures. The squirrel monkeys had access to all areas except the research rooms, which were only available to them during specific sessions. The observation windows that were used in this study are marked with red. Key: WS = west squirrel monkeys; $\mathrm{WC}=$ west capuchin monkeys (with squirrel monkey access); EC = east capuchin monkeys (with squirrel monkey access); ES = east squirrel monkeys. [Living Links to Human Evolution Research Centre, 2014].

Fig 2. The average proportions of time monkeys spent at the observation window for the three visitor group size categories. Letters $(\mathrm{a}, \mathrm{b}, \mathrm{c})$ indicate significant differences between those group categories that have matching letters. Error bars represent standard errors of the mean. 
589 Fig 3. The percentage of the total time each monkey spent at the window for each of the 590 three visitor categories. One monkey (Hugo) never came to the window.

592 Fig 4. Plots of each significant personality trait against the percentage difference between 593 the proportion of time spent at the window during the 'Large Group' condition and the 'No 594 Visitor' condition.

596 Fig 5. Plots of each significant personality trait against research participation scores. Higher 597 participation scores represent greater willingness to enter cubicles during training/experimental sessions. 